\title{
Novel Synthetic Method for the Vilsmeier-Haack Reagent and Green Routes to Acid Chlorides, Alkyl Formates, and Alkyl Chlorides
}

\author{
Yoshikazu Kimura, Daisuke Matsuura \\ Research and Development Department, Iharanikkei Chemical Industry Co. Ltd, Kambara, Shimizu-ku, Shizuoka, Japan \\ Email: kimura.yoshikazu@iharanikkei.co.jp
}

Received July 22, 2013; revised August 25, 2013; accepted September 12, 2013

Copyright (C) 2013 Yoshikazu Kimura, Daisuke Matsuura. This is an open access article distributed under the Creative Commons Attribution License, which permits unrestricted use, distribution, and reproduction in any medium, provided the original work is properly cited.

\begin{abstract}
An environmentally benign and practical preparation method for the Vilsmeier-Haack reagent (VH) has been developed by using phthaloyl dichloride with DMF in toluene or 2-chlorotoluene. Phthalic anhydride as the byproduct was recovered in high yield by simple filtration. Some aromatic acids have been transformed into the corresponding acid chlorides in good yields by employing the isolated VH. Treatment of primary or secondary alcohols with VH gave alkyl formates or alkyl chlorides by depending on the reaction conditions.
\end{abstract}

Keywords: Phthaloyl Dichloride; Vilsmeier-Haack Reagent; Acid Chlorides; Alkyl Formates; Alkyl Chlorides

\section{Introduction}

We have recently reported a new method for the preparation of the Vilsmeier-Haack reagent (VH) [1-6]. Our method obviates the use of toxic reagents such as phosgene, thionyl chloride, or phosphoryl chloride, which are used in the conventional method. It involves synthesis of $\mathrm{VH}$ reagent from $N, N$-dimethylformamide (DMF) and phthaloyl dichloride (OPC) in 1,4-dioxane (Scheme 1) [7]. Although 1,2-dimethoxyethane or tetrahydrofuran may also be used as solvent for this reaction, 1,4-dioxane specifically dissolves phthalic anhydride (PA) at five times its volume at room temperature, but it does not dissolve the $\mathrm{VH}$ reagent. $\mathrm{VH}$ reagent prepared through this method was isolated in almost pure form (based on its m.p. and ${ }^{1} \mathrm{H}$ NMR spectrum) by simple filtration under a nitrogen atmosphere. The process is highly atomefficient and generates no waste. PA, the byproduct, can be easily recovered from the 1,4-dioxane solution and reused as a material for OPC. However, 1,4-dioxane is a suspected carcinogen and forms peroxide under solvent recovery process. From the perspective of large-scale synthesis, the remaining issue to be addressed for this method is finding solvent substitutes that are safer and more economical.

Here, we report an improved method for the prepara- tion of $\mathrm{VH}$ reagent using toluene or 2-chlorotoluene (OCT) as solvents instead of dioxane. The $\mathrm{VH}$ reagent prepared from OPC and DMF has no impurity such as sulfur or phosphine derived from that prepared by the conventional method; therefore, we refer to the product as "OPC-VH reagent" in this article. In addition, we show some examples of synthesis of acid chlorides from carboxylic acids, alkyl formates from alcohols, and alkyl chlorides from alcohols using the OPC-VH reagent prepared through the new method. Products of these syntheses do have not contaminants such as sulfur or
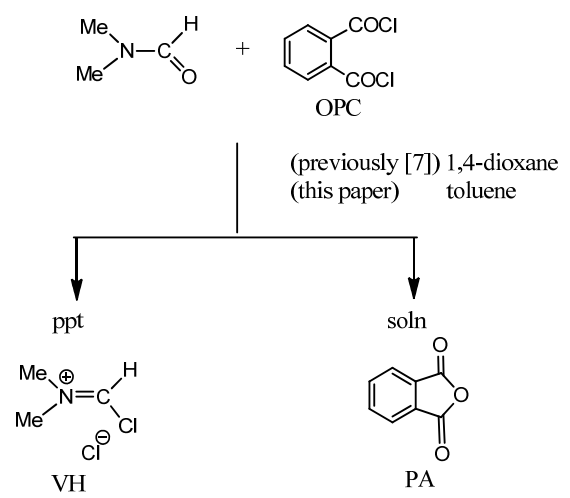

Scheme 1. New Preparation Method for the VilsmeierHaack Reagent. 
phosphine obtained through conventional methods.

\section{Results and Discussion}

\subsection{An Improved Method for Preparing the OPC-VH Reagent in Aromatic Solvents}

We first examined the use of toluene as a solvent for the preparation of the OPC-VH reagent. However, a sevenfold larger volume of toluene was needed to dissolve PA even at $70^{\circ} \mathrm{C}$. After several unsuccessful attempts, we finally found that a mixture of four times the volume of toluene plus an equivalent volume of DMF could dissolve PA at $35^{\circ} \mathrm{C}$. Furthermore, OCT may be preferred for industrial use because its flash point is higher than that of toluene.

Thus, a mixture of DMF (2 equiv: 1 equiv of reagent + lequiv of solvent) and OPC (1 equiv) in OCT (4 equiv) was stirred for $3 \mathrm{~h}$ at $50^{\circ} \mathrm{C}$ to afford the $\mathrm{OPC}-\mathrm{VH}$ reagent as crystals ( $86 \%$ yield), which were subsequently filtered and dried in vacuo. The dried OPC-VH reagent was characterized by its m.p. and ${ }^{1} \mathrm{H}$ NMR spectrum, which showed it to be free from contamination by PA and OCT. By simple concentration, filtration, and washing, PA was easily recovered in almost pure form from the filtrate of the OCT layer ( $91 \%$ yield).

\subsection{Examples of Synthesis of Acid Chlorides Using the OPC-VH Reagent}

Acid chlorides are important synthetic intermediates for the preparation of esters and amides. In particular, aromatic diacid dichlorides are key components of highperformance engineering thermoplastics such as polyamides, polyimides, and polybenzoxazoles [8], but a limited number of these compounds are commercially available in the reagent catalogs of Sigma-Aldrich and Tokyo Kasei Co.

Numerous reagents for the transformation of carboxylic acids into acid chlorides have been developed, such as thionyl chloride, phosphoryl chloride, oxalyl chloride, and phosgene. However, these chlorinating agents are not suitable for large-scale synthesis because of the hazardous nature of the reagent or byproducts formed. An environmentally benign and economical synthetic method for acid chlorides is still desired.

Using the OPC-VH reagent prepared in OCT or toluene, we next attempted the transformation of dicarboxylic acids into diacid dichlorides. We show two kinds of methods for synthesis of the diacid dichlorides as representative examples. In method A, a mixture of [1,1'-biphenyl]-4,4'-dicarboxylic acid and OPC-VH reagent (2.4 equiv) in 1,4-dioxane was stirred at $60^{\circ} \mathrm{C}$ for $4 \mathrm{~h}$. The appearance of the mixture changed from slurry to a clear solution. The entire mixture was cooled to room temperature to give pure [1,1'-biphenyl]-4,4'-dicarbonyl di- chloride in $82 \%$ yield after filtration. The compound was characterized by m.p. determination, IR spectroscopy, and GC-MS. In method B, OCT or toluene was used as a reaction solvent. A colorless solvent layer and brownish oil at the bottom of the flask (which may be excess VH and DMF) were obtained. The OCT or toluene layer was removed by decantation to separate the brownish oil at the bottom of the flask, and then concentrated to give a white solid. Although the need to remove the brownish matter from the solution was unexpected, the colorless acid chloride could be obtained.

Some dicarbonyl dichlorides similarly prepared are listed in Figure 1. As the only byproduct of this method is DMF, almost pure acid chlorides were obtained in high yield after evaporation of the solvent and DMF in vacuo.

\subsection{Synthesis of Alkyl Formates or Alkyl Chlorides from Alcohols with OPC-VH Reagent}

Reaction of alcohols with VH reagent to give alkyl formates or alkyl chlorides have been reported [9-14]. However, it is not clear what reaction conditions are required to prepare formates or chlorides selectively. Furthermore, the spectra and GC retention times of alcohols, formates, and chlorides are often similar, and in some cases, identification of the reaction product might not be achieved.

In the present study, we investigated the reaction of simple primary, secondary, and benzyl alcohols with the OPC-VH reagent. We used 1-hexanol and 2-hexanol as a substrate because each authentic sample and the spectrum data of hexyl derivatives could be easily obtained, and unambiguous characterization of those products was possible.

Reaction of 1-hexanol or 2-hexanol with OPC-VH reagent in chloroform in an ice bath gave the corresponding alkyl formate as a sole product (as determined by GC-MS) after quenching with an aqueous solution of sodium hydrogen carbonate. Performing the reaction at room temperature afforded a mixture of hexyl formates and hexyl chlorides. In the case of benzyl alcohol with OPC-VH reagent, a mixture of benzyl formate and benzyl chloride was obtained even at $0^{\circ} \mathrm{C}-5^{\circ} \mathrm{C}$. To obtain benzyl formate solely, it was necessary to run the reaction at around $-10^{\circ} \mathrm{C}$. Data on the selective preparation of alkyl formates are summarized in Figure 2.

Next, we examined some conditions that selectively give alkyl chlorides. Reaction of 1-hexanol with OPC$\mathrm{VH}$ reagent at $50^{\circ} \mathrm{C}$ for $3 \mathrm{~h}$ selectively gave 1-hexyl chloride (GC-MS) after quenching with aqueous sodium hydrogen carbonate.

Selective chlorination of secondary alcohol required a temperature higher than that used for primary alcohols; reaction of 2-hexanol with OPC-VH in dioxane was carried out at $80^{\circ} \mathrm{C}$ to obtain 2-hexyl chloride in nearly 


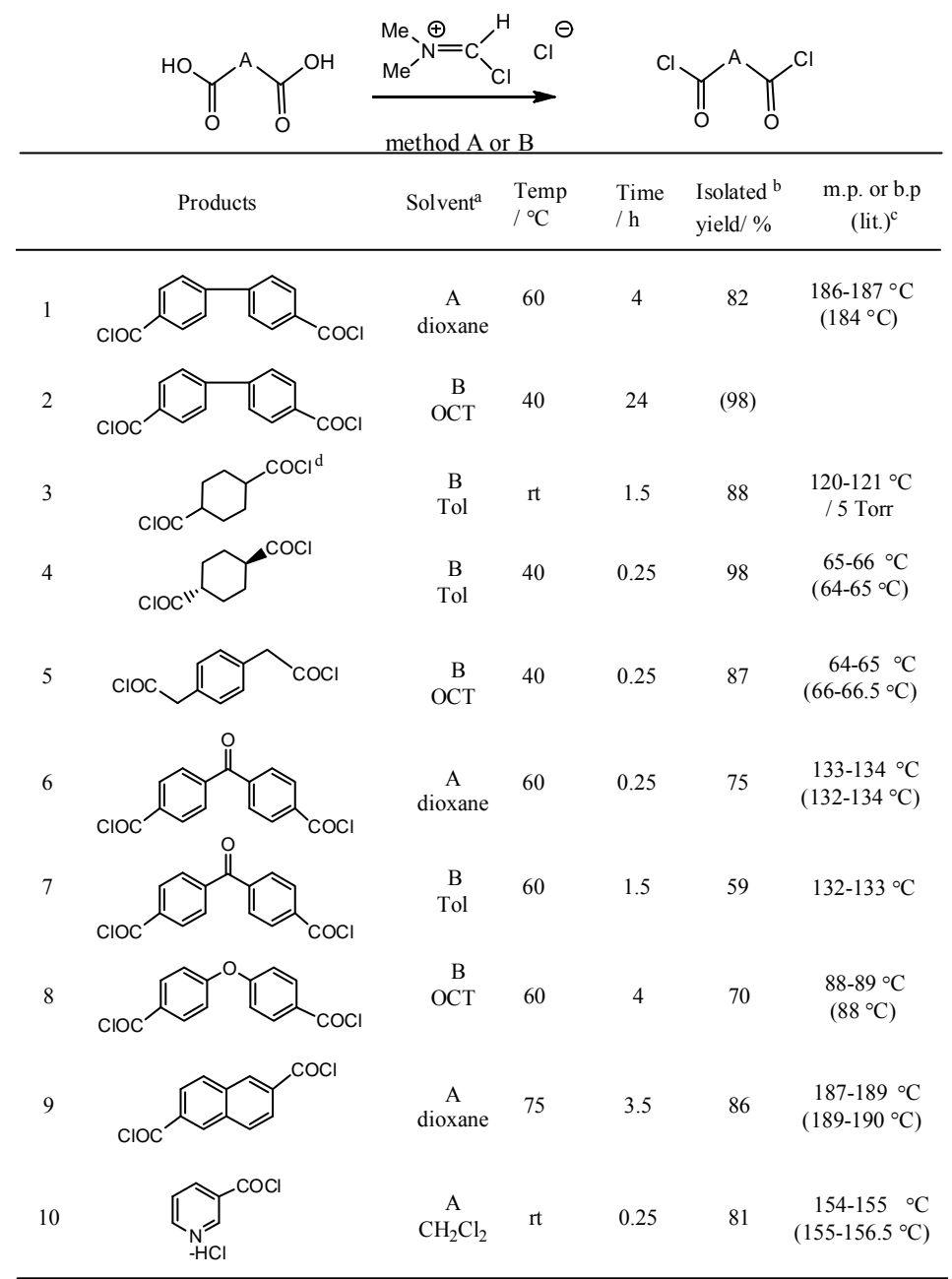

${ }^{a}$ Method A: Reaction, cooling, and simple filtration; Method B: Reaction, separation of organic layer, cooling, and filtration; See text; OCT: 2-chlorotoluene Tol: toluene barenthesis is refered to GC yield $\quad{ }^{c}$ see experimental section $\quad{ }^{d}$ cis/trans $=$ ca. $70 / 30$

Figure 1. Examples for Carbonyl dichloride prepared by the OPC-VH reagent.

Entry

Figure 2. Synthesis of alkyl formate from alcohol with OPC-VH reagent. 
quantitative yield.

Benzyl and cinnamyl chlorides were easily obtained at room temperature. 2-Cyclododecyl chloride could not be obtained even at $80^{\circ} \mathrm{C}$ in 1,4-dioxane (Figure 3).

We believe that the imidoyl intermediate 1 might be formed quickly in the reaction of alcohols with the OPC-VH reagent. It remained in solution and subsequently underwent hydrolysis with water to form alkyl formates (Scheme 2). On the other hand, alkyl chloride is formed by attack of the chloride anion on $\mathbf{1}$ during heating. Thus, heating and prolonged reaction time might be necessary for the selective formation of alkyl chloride.

\section{Experimental}

All melting points were determined with a Buchi melting point apparatus model B-545 and were uncorrected. IR spectra measurements were carried out with a Shimadzu IRAffinity-1 flourier transform infrared spectrophotometer. ${ }^{1}$ HNMR spectra were recorded with a Varian model Mercury-300 in $\mathrm{CDCl}_{3}$ with tetramethylsilane (TMS) as reference. GC-Mass spectra were recorded with a Shimadzu GCMS-QP2010 SE using a $0.320 \mathrm{~mm} \times 30 \mathrm{~m}$ column of DB-5.

Unless stated otherwise, all reagents and chemicals were obtained commercially and used without further purification.

\subsection{Preparation of OPC-VH Reagent from DMF with OPC in OCT}

OPC (125 g, $0.62 \mathrm{~mol})$ was added to DMF (135 g, 1.85 $\mathrm{mol})$ and OCT $(370 \mathrm{~mL})$ in a $1 \mathrm{~L}$ four-necked flask over a period of $10 \mathrm{~min}$ at room temperature. After the mixture was stirred at $50^{\circ} \mathrm{C}$ for $3 \mathrm{~h}$, the precipitated OPC-VH reagent was collected by filtration under a nitrogen atmosphere by using a glass filter, washed successively with OCT $(2 \times 150 \mathrm{~mL})$ and hexane $(150 \mathrm{~mL})$, and then dried in vacuo at $35^{\circ} \mathrm{C}-40^{\circ} \mathrm{C}$ for $2 \mathrm{~h}$. Yield: $68.0 \mathrm{~g}$ (86.1\%); m.p. $126.0^{\circ} \mathrm{C}-127.4^{\circ} \mathrm{C}$ (lit. m.p. $132^{\circ} \mathrm{C}$ [6], $126^{\circ} \mathrm{C}$ [7]); IR $\left(\mathrm{CHCl}_{3}\right): v=1699 \mathrm{~cm}^{-1}$; ${ }^{1} \mathrm{H}$ NMR $\left(\mathrm{CDCl}_{3}\right): \delta=3.98(\mathrm{~s}, 6 \mathrm{H}), 11.20(\mathrm{~s}, 1 \mathrm{H}) \mathrm{ppm}$. Peaks corresponding to DMF $(\delta=2.93,3.05,8.18 \mathrm{ppm})$ and liberated hydrogen chloride $(\delta=12.15 \mathrm{ppm})$ were also observed in amounts corresponding to $8 \%-10 \%$. The ${ }^{1} \mathrm{H}$ NMR spectrum of commercial VH reagent (Aldrich) showed signals at $\delta=4.00(\mathrm{~s}, 6 \mathrm{H}), 11.11(\mathrm{~s}, 1 \mathrm{H}) \mathrm{ppm}$,

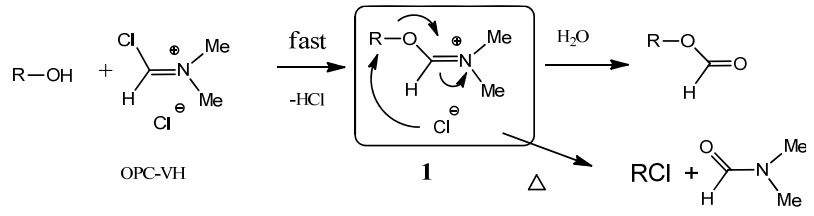

Scheme 2. Plausible reaction for alky1 formates and alky1 chlorides. along with those of DMF $(\delta=2.96,3.10,8.26 \mathrm{ppm})$, and $\mathrm{HCl}(\delta=12.81 \mathrm{ppm})$.

The aforementioned filtrate of the reaction mixture through a glass filter was concentrated to give crude PA, which was triturated with a mixture of hexane and toluene $(80 \mathrm{~mL}, 4 / 1)$. The PA was collected by filtration and washed with a mixture of hexane and toluene $(80 \mathrm{~mL}$, 4/1), and dried at $70^{\circ} \mathrm{C}$ for $1 \mathrm{~h}$. Yield: $83 \mathrm{~g} \mathrm{(91 \% ):} \mathrm{m.} \mathrm{p.}$ $131.0^{\circ} \mathrm{C}-131.4^{\circ} \mathrm{C}$ (lit. m.p. $130.8^{\circ} \mathrm{C}$ [15]); GC-MS: $\mathrm{m} / \mathrm{z}$ $=148\left(\mathrm{M}^{+}\right), 104$ (base peak), 76, 50.

\subsection{Synthesis of Acid Chlorides Using the OPC-VH Reagent}

\subsubsection{Representative Example for Method A: 4,4'-Biphenyldicarbonyl Dichloride}

A mixture of [1,1'-biphenyl]-4,4'-dicarboxylic acid (29.0 $\mathrm{g}, 0.12 \mathrm{~mol})$ and $\mathrm{OPC}-\mathrm{VH}$ reagent $(36.8 \mathrm{~g}, 0.29 \mathrm{~mol})$ in dioxane $(170 \mathrm{~mL})$ was stirred at $60^{\circ} \mathrm{C}$ for $4 \mathrm{~h}$. The mixture was cooled to room temperature, and then filtered to give [1,1'-biphenyl]-4,4'-dicarbonyl dichloride. Yield: $27.5 \mathrm{~g}(82 \%) ;$ m.p. $186^{\circ} \mathrm{C}-187^{\circ} \mathrm{C}$ (lit. m. p. $184^{\circ} \mathrm{C}$ [16]); IR (KBr): $v=1780 \mathrm{~cm}^{-1}$ (lit. $v=1778 \mathrm{~cm}^{-1}$ [17]); GCMS: $m / z=280\left(\mathrm{M}^{+}+2\right.$, relative intensity $\left.5 \%\right), 278\left(\mathrm{M}^{+}\right.$, $7 \%), 243\left(\mathrm{M}^{+}-35\right.$, base peak); GC-MS ( $\mathrm{Et}_{2} \mathrm{NH}$ treatment): $m / z=352\left(\mathrm{M}^{+}, 52 \%\right), 351(90 \%), 280$ (base peak).

\subsubsection{Synthesis of 2,6-Naphthalene Dicarbonyl Dichloride}

2,6-Naphthalene dicarboxylic acid (37.0 g, $0.17 \mathrm{~mol})$ was added to a slurry of OPC-VH reagent $(25.0 \mathrm{~g}, 0.20 \mathrm{~mol})$ in dioxane $(280 \mathrm{~mL})$ at room temperature. The mixture was stirred at $75^{\circ} \mathrm{C}$ for $3.5 \mathrm{~h}$ until a clear solution was formed. The solution was filtered through a glass filter to remove a small amount of insoluble matter, and then cooled to room temperature. The precipitate was collected by filtration, washed with dioxane $(100 \mathrm{~mL})$, and then dried in vacuo to give 2,6-naphthalene dicarbonyl dichloride. Yield: $37.1 \mathrm{~g}(86 \%)$; m.p. $187^{\circ} \mathrm{C}-189^{\circ} \mathrm{C}$. (lit. m.p. $189^{\circ} \mathrm{C}-190^{\circ} \mathrm{C}[18]$ ); IR (KBr): $v=1751 \mathrm{~cm}^{-1}$ (lit. $v$ $\left.=1750 \mathrm{~cm}^{-1}[18]\right) ;$ GC-MS: $m / z=254\left(\mathrm{M}^{+}+2\right.$, relative intensity 11\%), $252\left(\mathrm{M}^{+}, 17 \%\right), 219(33 \%), 217\left(\mathrm{M}^{+}-35\right.$, base peak).

\subsubsection{Synthesis of 4,4'-Carbonyldibenzoyl Chloride} 4,4'-Carbonyldibenzoic acid (5.26 g, $19.5 \mathrm{mmol})$ was added to a slurry of OPC-VH reagent $(5.50 \mathrm{~g}, 43 \mathrm{mmol})$ in dioxane $(20 \mathrm{~mL})$ at room temperature. The mixture was stirred at $60^{\circ} \mathrm{C}$ for $0.25 \mathrm{~h}$ until a clear solution was formed, and cooled to room temperature. The precipitate was collected by filtration, washed with dioxane $(10 \mathrm{~mL})$, and then dried in vacuo to give 4,4'-carbonyldibenzoyl chloride. Yield: $4.49 \mathrm{~g}(75 \%)$; m.p. $133^{\circ} \mathrm{C} 134^{\circ} \mathrm{C}$ (lit. m.p. $\left.132^{\circ} \mathrm{C}-134^{\circ} \mathrm{C}[19]\right) ;$ GCMS: $m / z=306\left(\mathrm{M}^{+}, 4 \%\right), 271$ $\left(\mathrm{M}^{+}-35\right.$, base peak). 


(2)

Figure 3. Synthesis of alkyl chloride from alcohol with OPC-VH reagent.

\subsubsection{Nicotinyl Chloride Hydrochloride}

To a slurry of OPC-VH reagent $(1.4 \mathrm{~g}, 11.0 \mathrm{mmol})$ in dichloromethane $(25 \mathrm{~mL})$ was added nicotinic acid $(1.15$ $\mathrm{g}, 0.93 \mathrm{mmol}$ ). The mixture was stirred at room temperature for $0.25 \mathrm{~h}$ to precipitate a white solid. Filtration, washing, and drying gave white crystals of the title compound, which was purified by sublimation $\left(105^{\circ} \mathrm{C}-\right.$ $\left.110^{\circ} \mathrm{C}, 0.6 \mathrm{kPa}\right)$. Yield: $1.34 \mathrm{~g}(81 \%)$; m.p. $154^{\circ} \mathrm{C}-$ $155^{\circ} \mathrm{C}$ (lit. m.p. $155^{\circ} \mathrm{C}-156.5^{\circ} \mathrm{C}$ [20]); GC-MS (Et $\left.{ }_{2} \mathrm{NH}\right)$ : $m / z=178\left(\mathrm{M}^{+}\right)$.

\subsubsection{Representative Example for Method B: 4,4'-Oxybisbenzoyl Dichloride}

A $1 \mathrm{~L}$ four-necked flask was charged with 4,4'-oxybis (benzoic acid) (45 g, $0.17 \mathrm{~mol})$ and $\mathrm{OPC}-\mathrm{VH}$ reagent (50 g, $0.39 \mathrm{~mol})$ in OCT $(300 \mathrm{~mL})$, and the mixture was stirred at $60^{\circ} \mathrm{C}$ for $4 \mathrm{~h}$. The appearance of the mixture changed from a slurry to a clear solution. The OCT layer was separated by decantation to remove brownish oil at the bottom of the flask, concentrated to a volume of about $70 \mathrm{~mL}$, and then kept at $10^{\circ} \mathrm{C}-15^{\circ} \mathrm{C}$. The precipitated 4,4'-oxybis(benzoyl dichloride) was collected by filtration and then dried in vacuo at $40^{\circ} \mathrm{C}$ for $2 \mathrm{~h}$ to give the pure compound. Yield: $35.8 \mathrm{~g}(70 \%)$; m.p. $88^{\circ} \mathrm{C}-$ $89^{\circ} \mathrm{C}$ (lit. m. p. $88^{\circ} \mathrm{C}$ [21]); IR (KBr): $v=1759,1732$ $\mathrm{cm}^{-1}$ (lit. $v=1767,1739 \mathrm{~cm}^{-1}$ [21]); GC-MS: $m / z=259$
( $\mathrm{M}^{+}-35$, base peak); GC-MS of the diethylamide derivative: $m / z=368\left(\mathrm{M}^{+}\right.$, relative intensity $9 \%$ ), 296 (base peak).

\subsubsection{Synthesis of Trans-Cyclohexane-1,4-dicarbonyl Dichloride}

A mixture of trans-cyclohexane-1,4-dicarboxylic acid (3.2 g, $18.6 \mathrm{mmol})$, OPC-VH reagent $(5.8 \mathrm{~g}, 45.3 \mathrm{mmol})$, and toluene $(30 \mathrm{~mL})$ was stirred at room temperature for $1 \mathrm{~h}$ to give a clear solution. The toluene layer was separated by decantation and the brownish oil at the bottom of the flask was removed. The toluene layer was then concentrated in vacuo to afford white crystals of nearly pure trans-cyclohexane-1,4-dicarbonyl dichloride. Yield: $3.8 \mathrm{~g}(97 \%)$ ) m.p. $65^{\circ} \mathrm{C}-66^{\circ} \mathrm{C}$ (lit. m.p. $64^{\circ} \mathrm{C}-66^{\circ} \mathrm{C}[17]$ ); IR $\left(\mathrm{CHCl}_{3}\right): v=1790 \mathrm{~cm}^{-1}$; GC-MS: $m / z=208\left(\mathrm{M}^{+}\right)$, $173\left(\mathrm{M}^{+}-35\right), 145,117,109,81$ (base peak).

\subsubsection{Synthesis of 1,4-Phenylene-Diacetyl Chloride}

A mixture of 1,4-phenylene diacetic acid $3.88 \mathrm{~g}(20.0$ $\mathrm{mmol})$, OPC-VH reagent $(5.8 \mathrm{~g}, 45.3 \mathrm{mmol})$, and toluene $(40 \mathrm{~mL})$ was stirred at $35^{\circ} \mathrm{C}-40^{\circ} \mathrm{C}$ for $0.25 \mathrm{~h}$. The toluene layer was separated by decantation and concentrated in vacuo to give 1,4-phenylene-diacetyl chloride. Yield: 4.0 g $(87 \%)$; m.p. $65^{\circ} \mathrm{C}-67^{\circ} \mathrm{C}$. (lit. m.p. $66^{\circ} \mathrm{C}-66.5^{\circ} \mathrm{C}$ [22]) GCMS ( $\mathrm{Et}_{2} \mathrm{NH}$ treatment): $m / \mathrm{z}=304\left(\mathrm{M}^{+}, 17 \%\right)$, 
100 (base peak).

\subsection{Synthesis of Alkyl Formates from Primary and Secondary Alcohols Using the OPC-VH Reagent}

\subsubsection{Synthesis of 1-Hexyl Formate}

To OPC-VH reagent $(2.3 \mathrm{~g}, 18 \mathrm{mmol})$ dissolved in dry chloroform $(10 \mathrm{~mL})$ at $3^{\circ} \mathrm{C}-5^{\circ} \mathrm{C}$ was added a solution of 1-hexanol $(1.4 \mathrm{~g}, 13.7 \mathrm{mmol})$ in dry chloroform $(5 \mathrm{~mL})$ over a period of $10 \mathrm{~min}$. The mixture was stirred for a further $10 \mathrm{~min}$ at the same temperature, and then poured with vigorous stirring into a mixture of ice, sodium hydrogen carbonate solution $(50 \mathrm{~mL})$ and dichloromethane $(20 \mathrm{~mL})$. The organic layer was separated and the aqueous layer was extracted with dichloromethane $(2 \times 20$ $\mathrm{mL}$ ). The combined organic layers was washed with water $(2 \times 30 \mathrm{~mL})$, dried over anhydrous sodium sulfate, and concentrated in vacuo to afford nearly pure 1-hexyl formate ( $1.5 \mathrm{~g}, 84 \%$ yield) as a colorless oil, which was identified by GC-MS and by comparison with an authentic spectrum (SDBS [23]).

\subsubsection{Synthesis of 2-Hexyl Formate}

A similar treatment of 2-hexanol with OPC-VH reagent gave 2-hexyl formate. GC-MS: $m / z=84,73,69,56,55$. Its spectrum is highly similar to that of 2-hexyl chloride, but both retention times differ by more than $2 \mathrm{~min}$. A methanol solution of the 2-hexyl formate sample was stirred with $1 \mathrm{M} \mathrm{NaOH}$ at room temperature for $0.5 \mathrm{~h}$, extracted with ether, and then completely identified as 2-hexanol by GC-MS [23].

\subsubsection{Synthesis of 2-Cyclododecyl Formate}

To OPC-VH reagent $(2.1 \mathrm{~g}, 16.5 \mathrm{mmol})$ dissolved in dry chloroform $(10 \mathrm{~mL})$ at $3^{\circ} \mathrm{C}-5^{\circ} \mathrm{C}$ was added a solution of cyclododecanol $(2.4 \mathrm{~g}, 13.0 \mathrm{mmol})$ in dry chloroform $(8$ $\mathrm{mL}$ ) over a period of $10 \mathrm{~min}$. The mixture was stirred for a further $30 \mathrm{~min}$ at the same temperature, and then poured with vigorous stirring into a mixture of ice, sodium hydrogen carbonate solution $(50 \mathrm{~mL})$, and dichloromethane $(20 \mathrm{~mL})$. The organic layer was separated and the aqueous layer was extracted with dichloromethane $(3 \times 20 \mathrm{~mL})$. The combined organic layers was washed with water $(2 \times 30 \mathrm{~mL})$, dried over anhydrous sodium sulfate, and then concentrated in vacuo to afford $2.89 \mathrm{~g}$ of yellow oil, which was submitted to bulb-to-bulb distillation $\left(150^{\circ} \mathrm{C}-160^{\circ} \mathrm{C}, 3\right.$ Torr) to give the colorless 2-cyclododecyl formate. Yield: $2.51 \mathrm{~g}(90 \%)$; IR (neat): $v=1724 \mathrm{~cm}^{-1}$; GC-MS: $m / z=166\left(\mathrm{M}^{+}-45\right) ;{ }^{1} \mathrm{H}$ NMR $\left(\mathrm{CDCl}_{3}\right): \delta=1.35-1.80(\mathrm{~m}, 22 \mathrm{H}), 5.10-5.18(\mathrm{~m}, 1 \mathrm{H})$, $8.05(\mathrm{~s}, 1 \mathrm{H})$.

\subsubsection{Synthesis of Benzyl Formate}

To OPC-VH reagent $(1.4 \mathrm{~g}, 11 \mathrm{mmol})$ dissolved in dry chloroform $(10 \mathrm{~mL})$ at $-10^{\circ} \mathrm{C}$ was added a solution of benzyl alcohol $(0.78 \mathrm{~g}, 7.2 \mathrm{mmol})$ in dry chloroform (3 $\mathrm{mL})$ over a period of $8 \mathrm{~min}$. Benzyl formate $(0.75 \mathrm{~g}, 77 \%$ yield) was isolated by a similar work up to 3.3.1. It was then identified by GC-MS and its spectrum was compared against that of an authentic sample (SDBS): $\mathrm{m} / \mathrm{z}=$ $136\left(\mathrm{M}^{+}\right), 108,107,91,90$.

In a case of reaction of benzyl alcohol with OPC-VH reagent at $3^{\circ} \mathrm{C}-5^{\circ} \mathrm{C}$, a mixture of benzyl chloride $(24 \%)$ and benzyl formate $(76 \%)$ was obtained, as confirmed by GCMS.

\subsection{Synthesis of Alkyl Chlorides from Alcohol Using the OPC-VH Reagent: Synthesis of 1-Hexyl Chloride}

To OPC-VH reagent $(2.3 \mathrm{~g}, 18 \mathrm{mmol})$ dissolved in dry chloroform $(10 \mathrm{~mL})$ at room temperature was added a solution of 1-hexanol $(1.4 \mathrm{~g}, 13.7 \mathrm{mmol})$ in dry chloroform $(5 \mathrm{~mL})$ over a period of $5 \mathrm{~min}$. The mixture was stirred at $60^{\circ} \mathrm{C}$ for $2 \mathrm{~h}$, and then poured into ice water $(50$ $\mathrm{mL})$. The organic layer was separated and the aqueous layer was extracted with dichloromethane $(2 \times 20 \mathrm{~mL})$. The combined organic layers was washed with water $(2 \times$ $30 \mathrm{~mL}$ ), dried over anhydrous sodium sulfate, and then concentrated in vacuo to give nearly pure 1-hexyl chloride $(1.39 \mathrm{~g}, 84 \%$ yield $)$ which was identified by GC-MS: $m / z=93,91,69,56,55$. The GC-MS spectrum was identical to that of a reported one [23].

\section{Conclusion}

As the preparation method for $\mathrm{VH}$ reagent in the present study is readily accessible and environmentally benign, it should find wide acceptance for laboratory as well as industrial use.

\section{REFERENCES}

[1] A. Vilsmeier and A. Haack, "Über die Einwirkung von Halogenphosphor auf Alkyl-Formanilide. Eine Neue Methode zur Darstellung Sekundärer und Tertiärer $p$-Alkylamino-benzaldehyde," Chemische Berichte, Vol. 60, No. 1, 1927, pp. 119-122.

http://dx.doi.org/10.1002/cber.19270600118

[2] C. M. Marson, "Reactions of Carbonyl Compounds with (Monohalo) Methyleniminium Salts (Vilsmeier Reagents)," Tetrahedron, Vol. 48, No. 18, 1992, pp. 3659-3726. http://dx.doi.org/10.1016/S0040-4020(01)92263-X

[3] H. H. Bosshard, R. Mory, M. Schmid and H. Zollinger, "Eine Method zur Katalysierten Herstellung von Carbonsaure- und Sulfosaure-Chloriden mit Thionylchloride," Helvetica Chimica Acta, Vol. 42, No. 5, 1959, pp. 1653 1658. http://dx.doi.org/10.1002/hlca.19590420526

[4] H. Eilingsfeld, M. Seefelder and H. Weidinger, "Amidchloride und Carbamidchloride," Angewandte Chemie, Vol. 72, No. 22, 1960, pp. 836-845. 
http://dx.doi.org/10.1002/ange.19600722

[5] D. R. Hepburn and H. R. Hudson, "Factors in the Formation of Isomerically and Optically Pure Alkyl Halides. Part XI. Vilsmeier Reagents for the Replacement of a Hydroxy-Group by Chlorine or Bromine," Journal of the Chemical Society, Perkin Transactions 1, No. 7, 1976, pp. 754-757. http://dx.doi.org/10.1039/P19760000754

[6] Z. Arnold, "Structure of the Formylation Agent from Dimethylformamide and Phosgene," Collection of Czechoslovak Chemical Communications, Vol. 24, 1959, pp. 40484049.

[7] Y. Kimura, D. Matsuura, T. Hanawa and Y. Kobayashi, "New Preparation Method for Vilsmeier Reagent and Related Imidoyl Chlorides," Tetrahedron Letters, Vol. 53, No. 9, 2012, pp. 1116-1118. http://dx.doi.org/10.1016/j.tetlet.2011.12.087

[8] K. Fukukawa and M. Ueda, "Recent Development of Photosensitive Polybenzoxazoles," Polymer Journal, Vol. 38, No. 1, 2006, pp. 405-418.

http://dx.doi.org/10.1295/polymj.38.405

[9] K. Morita, S. Noguchi and M. Nishikawa, "Studies in Steroids. XIII. Formylation of Steroid Alcohols with Dimethylformamide-Phosgene Complex," Chemical \& Pharmaceutical Bulletin, Vol. 7, No. 8, 1959, pp. 896-897. http://dx.doi.org/10.1248/cpb.7.896

[10] J. Barluenga, P. J. Campos, E. Gonzalez-Nunez and G. Asensio, "General Method for the Formylation of Alcohols with Dimethylformamide: An Extension of the Vilsmeier-Haack Reaction," Synthesis, No. 4, 1985, pp. 426428. http://dx.doi.org/10.1055/s-1985-31228

[11] I. Fernandez, B. Garcia, S. Munoz, J. R. Pedro and R. D. 1 Salud, "A Simple Convenient Procedure for the Synthesis of Formate Esters and Alkyl Iodides from Alcohols Using the System Thionyl Chloride-Dimethylformamide-Alkaline Iodide," Synlett, No. 7, 1993, pp. 489-490 http://dx.doi.org/10.1055/s-1993-22501

[12] M. Benazza, R. Uzan, D. Beaupere and G. Demailly, "Direct Regioselective Chlorination of Unprotected Hexitols and Pentitols by Vilsmeier and Haack's Salt," Tetrahedron Letters, Vol. 33, No. 34, 1992, pp. 4901-4904. http://dx.doi.org/10.1016/S0040-4039(00)61228-5

[13] M. Yoshihara, T. Eda, K. Sakaki and T. Maeshima, "Conversion of Alcohols to Alkyl Halides Using Iminium Salts,"
Synthesis, No. 9, 1980, pp. 746-748. http://dx.doi.org/10.1055/s-1980-29199

[14] A. Dubey, A. K. Upadhyay and P. Kumar, "Pivaloyl Chloride/DMF: A New Reagent for Conversion of Alcohols to Chlorides," Tetrahedron Letters, Vol. 51, No. 4, 2010, pp. 744-746.

http://dx.doi.org/10.1016/j.tetlet,2009,11,131

[15] S. Budavari, "The Merck Index," 12 Edition, Merck \& Co., Inc. Whitehouse Station, New Jersey, 1996.

[16] R. C. Schreyer and W. Del, "Production of Aromatic Acid Halides," US Patent 2856425, 1958.

[17] K. A. Burdett, "An Improved Acid Chloride Preparation via Phase Transfer Catalysis," Synthesis, No. 6, 1991, pp. 441-442. http://dx.doi.org/10.1055/s-1991-26487

[18] R. Kluger, L. Shen. H. Xiao and R. T. Jones "Systematically Cross-Linked Human Hemoglobin: Functional Effects of $10 \AA$ Spans between Beta Subunits at Lysine-82," Journal of the American Chemical Society, Vol. 118, No. 37, 1996, pp. 8782-8786. http://dx.doi.org/10.1021/ja961443z

[19] M. W. Wolf, R. E. Brown and L. A. Singer, "Deactivation of Benzophenone Triplets via Exciplex Formation. Evidence for Dual Reaction Pathways," Journal of the American Chemical Society, Vol. 99, No. 2, 1977, pp. 526-531. http://dx.doi.org/10.1021/ja00444a036

[20] E. Spath and H. Spitzer, "Zur Kenntnis der Chloride einiger einfacher Pyridin- und Chinolin-carbonsäuren," Berichte, Vol. 59, Vo. 7, 1926, pp. 1477-1486. http://dx.doi.org/10.1002/cber.19260590724

[21] S. Nishizaki and A. Fukami, "Properties of Polyamides Containing 4,4'-Oxydiphenylene Groups," Kogyo Kagaku Zasshi, Vol. 70, No. 9, 1967, pp. 1607-1609.

[22] C. S. Marvel and E. A. Kraiman, "Polythiolesters. II. Preparation in Emulsions," Journal of Organic Chemistry, Vol. 18, No. 6, 1953, pp. 707-714.

http://dx.doi.org/10.1021/jo01134a016

[23] SDBS: A Free Site of Spectral Database for Organic Compounds Organized by National Institute of Advanced Industrial Science and Technology (AIST), Japan. http://sdbs.riodb.aist.go.jp/sdbs/cgi-bin/cre_index.cgi?lan $\mathrm{g}=\mathrm{jp}$ 